\title{
PALENQUE COMO IMAGO MUNDI Y LA PRESENCIA EN ELLA DE ITZAMNÁ ${ }^{1}$
}

\author{
Mercedes de la Garza Camino \\ Centro de Estudios Mayas, \\ Instituto de Investigaciones Filológicas, UNAM
}

Ciertamente en Palenque se halla un reservorio extraordinario e inabarcable de información sobre la religión maya: su pensamiento religioso, sus figuras divinas, sus ritos y la situación y estatus sobrenatural de sus gobernantes. Muchos nos hemos afanado por comprender desde muy distintas perspectivas los complejos símbolos que pueblan sus obras escultóricas y arquitectónicas, y cada día surgen nuevas luces, sobre todo por los hallazgos arqueológicos y los notables avances de la epigrafía, desde mediados del siglo $\mathrm{xx}$, que obligan a repensar las distintas interpretaciones.

Pero considero que, además, el análisis comparativo de los símbolos palencanos con los de otros sitios mayas clásicos, con los del Posclásico, así como con los mitos y referencias a los dioses y a los rituales en los textos escritos después de la conquista por los propios mayas, y también en algunas fuentes españolas, es sin duda esencial para este acercamiento, por lo menos desde nuestro enfoque disciplinario, que es el de la historia de las religiones.

En la investigación sobre la religión de Palenque (o de cualquier otra ciudad maya) poco se logra desde una sola perspectiva, y los análisis comparativos, tanto de las diversas fuentes como de los distintos estudios realizados por los mayistas actuales, pueden enriquecer todo tipo de enfoques, de tal manera que el investigador no piense que cada nueva interpretación suya es un descubrimiento propio.

A mediados del siglo xx era fuertemente condenada la comparación de lo clásico con lo posclásico, y mucho más con los documentos coloniales, como pensaba, entre otros, George Kubler respecto de los mayas. En las décadas de los sesenta y setenta otros nos dimos cuenta de que los textos indígenas coloniales contenían símbolos, mitos y ritos mayas, cuyas primeras manifestaciones parecían estar en relieves y textos clásicos, así como en los códices. ${ }^{2}$ Desde entonces varios estudiosos de la religión maya hemos venido realizando este tipo de análisis comparativos que poco a poco se fueron enriqueciendo, confirmando o desechando, gracias a los avances arqueológicos, epigráficos e iconográficos

\footnotetext{
${ }^{1}$ Aquí usaré el nombre tradicional del dios, salvo en los casos en que cito a otro autor.

${ }^{2}$ Hay que reconocer que Eric Thompson y Alberto Ruz Lhuillier se cuentan entre los primeros en realizar análisis comparativos, se esté o no de acuerdo con ellos.
} 
posteriores. Hacia los años ochenta otros investigadores empezaron a hallar en diversas obras clásicas a los personajes míticos del Popol Vuh (como Floyd Lounsbury, 1980), y hoy día, con muy distintas ideas y posiciones metodológicas y disciplinarias, la inmensa mayoría de los investigadores de la religión maya ha desechado ya la idea de que los datos del periodo Posclásico o los que aportan las fuentes escritas en el periodo colonial son ajenos a la religión del Clásico, pues al fin ya se ha advertido en todos los ámbitos de la investigación mayista que las creencias básicas de un pueblo constituyen "estructuras de larga duración”, como afirmó Fernand Braudel (1974), ${ }^{3}$ por permanecer casi inalterables durante siglos. Y todavía más allá, hoy día es comúnmente aceptada la comparación de la religión maya actual con la prehispánica y colonial, precisamente por la misma razón. ${ }^{4}$

Por otra parte, en mi opinión, sin que ello implique hacer generalizaciones infundadas, se debe tener mucho cuidado en interpretar las distintas manifestaciones o advocaciones de un dios como deidades diferentes, así como delimitar con toda precisión los atributos y funciones de un dios, pues esto puede contravenir el pensamiento religioso de un pueblo. Yo pienso que ubicar a los dioses en casilleros separados y claramente definidos, a la manera del pensamiento racionalista y positivista occidental, expresa una falta de comprensión de la plurivalencia de los símbolos religiosos y de la contradicción y ambigüedad que en cualquier religión tienen las expresiones de la vivencia de lo sagrado: mitos, ritos, imágenes y símbolos. Y en el caso de las figuras divinas de los mayas, encontramos que la presencia de los rasgos de una deidad en otra es muy frecuente en sus imágenes plásticas, y las funciones de los dioses de ningún modo son unívocas. En el estudio de las religiones hay que perder el miedo a la contradicción.

Aquí me limitaré a exponer, a grandes rasgos, prescindiendo por supuesto del análisis detallado que sustenta mis afirmaciones, el simbolismo cosmológico que se manifiesta en algunas construcciones y relieves de la ciudad de Palenque, pues éste es básico para entender la presencia en ella de Itzamná, el dios supremo celeste y creador de los mayas. A la vez, dicho simbolismo se confirma con la significación de las deidades palencanas y con el contenido simbólico religioso de los tableros del grupo de las Cruces, de la lápida de la tumba de K'inich Janahb' Pakal y de los textos del Templo XIX, obras tan ricas y complejas en su simbolismo religioso que obviamente son y pueden ser objeto de múltiples interpretaciones y lecturas.

\footnotetext{
${ }^{3}$ Ver también Reichel-Dolmatof, 1988.

${ }^{4}$ La conciencia hermenéutica de nuestro tiempo consiste en el reconocimiento de múltiples interpretaciones científicas y en la aceptación de que todas son válidas en tanto que se hacen desde distintas perspectivas y metodologías. Incluso la posibilidad de lectura de un texto no implica univocidad, pues hasta de textos escritos en nuestra escritura alfabética y en nuestra propia lengua puede haber distintas interpretaciones. Pero la diversidad de la hermenéutica no significa arbitrariedad; no se pierde el rigor científico por aceptar la diversidad, sino más bien se invalida toda pretensión de
} 


\section{Palenque como imago mundi}

Los espacios sagrados (De la Garza, 1998: 71-80) son aquellos sitios naturales que, por sus peculiaridades extraordinarias, son considerados lugares de encuentro del ser humano con los dioses. En Palenque, algunos de esos lugares naturales sagrados, según las inscripciones, parecen haber sido Lakamhá’, "Grandes aguas”, el manantial del que desciende el arroyo Otulum, detrás del Templo XIX, y Yemal K'uk' Lakam Witz, "Gran montaña del quetzal descendente” (mencionado en los textos del grupo de la Cruz y asociado con Lakamhá'), que corresponde al Mirador, elevada montaña situada detrás del grupo de las Cruces, que domina el principal sector ceremonial del sitio (Stuart, 2006: 92).

Por lo general, en los lugares naturales divinos el hombre construye otros espacios sagrados que van desde caminos y altares en las montañas o cuevas, hasta conjuntos de edificaciones ceremoniales. Los creadores de estos ámbitos sagrados piensan que en ellos se concentran las energías divinas convocadas en los ritos, de tal manera que se convierten en centros desde los cuales se puede influir en el cosmos íntegro. La constante actividad ritual hace que el poder sagrado se vaya acrecentando y que se requieran ampliaciones y renovaciones arquitectónicas en las mismas construcciones; así, un templo se erige sobre otro, una plaza encima de otra plaza. Las nuevas obras se sobreponen a las antiguas, no con fines pragmáticos, como se ha afirmado algunas veces, sino para incorporar a la nueva construcción la fuerza divina acumulada, porque el hombre religioso considera que los dioses reconocen los sitios de encuentro con los hombres y retornan a aquellos cuando se les invoca en el rito.

Además, el espacio sagrado se crea como una imagen reducida y concentrada del mundo, como un microcosmos. Y cada uno de estos microcosmos posee a su vez uno o varios centros, considerados todos ellos "centro del mundo", ya que la geografía sagrada admite la contradicción y la plurivalencia. Los ámbitos ceremoniales de las ciudades mayas son, así, axis mundi e imágenes del cosmos, al mismo tiempo que réplicas de los lugares primigenios en los que se llevó a cabo la creación del orbe, pues generalmente se piensa que ese primer acontecimiento ocurrió en el centro del mundo.

Sin duda en estos centros se realizaban ritos para revivir periódicamente el acontecimiento primigenio como una forma de revitalizar el cosmos, así como para emprender viajes sagrados a las regiones celeste e infraterrestre. Dicho de otro modo, los mitos cosmogónicos y cosmológicos, casi siempre inseparables, constituyen el modelo de las construcciones, como ocurre en todas las ciudades antiguas de los pueblos religiosos, para los cuales la ciudad es una imago mundi. ${ }^{5}$

que exista un camino único de conocimiento histórico, social y humanístico en general. Se invalida el dogmatismo, que ha hecho tanto daño a la investigación científica.

${ }^{5}$ Debo aclarar que yo entiendo los términos cosmogónico, cosmológico y cosmos en su significación literal originaria: cosmos: el orden de todo lo que existe, universo entero; cosmogónico: lo relativo al origen del cosmos; y cosmológico: lo relativo a la estructura del cosmos. 
Múltiples son las obras arquitectónicas y escultóricas que reflejan la cosmología maya y corroboran que las imágenes expresadas en los mitos de las fuentes indígenas coloniales y conservadas, de algún modo, en algunos grupos mayances actuales, estaban ya presentes en el periodo Clásico.

En los mitos recogidos en la época colonial, entre los que destacan los contenidos en los Libros de Chilam Balam, particularmente el de Chumayel, la imagen del cosmos se presenta como una estructura de tres niveles: el cielo, de trece estratos; la tierra, como una plancha plana cuadrangular, y el inframundo de nueve niveles. ${ }^{6}$ Y esta estructura está dividida a su vez en cuatro sectores (Sotelo, 1988), que al parecer fueron determinados por la trayectoria anual del Sol, es decir, que así como el Sol y su movimiento crean el tiempo, también determinan el espacio, ya que la concepción de la cuadruplicidad terrestre, que hallamos también en varios otros pueblos antiguos, ${ }^{7}$ parece ser resultado de la experiencia que se vive gracias al fenómeno natural de la salida y puesta del Sol, en la línea donde el cielo y la tierra se unen a lo largo del ciclo anual del astro. Esta trayectoria distingue tanto los cuatro rumbos o sectores cósmicos como las cuatro estaciones, uniéndose en la cuadruplicidad el espacio y el tiempo.

Los símbolos mayas de la cuadruplicidad y de la quinta dirección o centro del cosmos son diversos. Destaca en primer lugar el glifo del Sol, que es una flor de cuatro pétalos pues, como señalé arriba, es él quien rige el tiempo y, además, quien determina la división cuatripartita del espacio. Otro glifo que representa geométricamente el cosmos es el llamado quincunce, símbolo que hallamos en otras culturas mesoamericanas, como la náhuatl, con una significación igual.

Hay también imágenes de los cuatro rumbos en los códices, como la muy conocida de las páginas 75 y 76 del Códice Madrid, que representa los cuatro sectores cósmicos y, en el centro, el árbol que funge como axis mundi, bajo el cual está sentado el dios supremo Itzamná en su aspecto antropomorfo y con su pareja o su aspecto femenino.

Pero el símbolo principal del Centro del Mundo en el Libro de Chilam Balam de Chumayel es una gran ceiba verde, denominada "Gran Madre Ceiba" (1985: 89), que atraviesa los tres niveles cósmicos comunicándolos. Esta imagen del árbol axis mundi es una de las más comunes del simbolismo del centro; se halla en la India védica, China, la mitología germánica y muchas otras religiones (Champeaux y Sterckx, 1989: 343-446).

Hay también ceibas en los cuatro rumbos: roja en el este, negra en el oeste, blanca en el norte y amarilla en el sur; cada una de ellas tiene en lo alto un ave, del mismo color. La ceiba verde, aunque el mito no lo menciona, debía tener

\footnotetext{
${ }^{6}$ Véase en el Chilam Balam de Chumayel el pasaje llamado "Libro de los antiguos dioses", traducido por Médiz Bolio, y "La creación del mundo", traducido por Roys.

${ }^{7}$ Por ejemplo, en Babilonia, Persia, China y la India; en esta última la tierra se llamó "chaturanta" (de cuatro extremos) (Biedermann, "Cuadrado", 1993; Champeaux y Sterckx, 1989: 37-44, y Lurker, 1992: 127).
} 
también su ave en la cima, y ésta debía ser verde; y precisamente es verde el ser sagrado que está en el cielo, según el mismo texto, porque se trata del Canhel, dragón con plumas de quetzal o yaxum (1985: 88), ${ }^{8}$ una de las advocaciones de la deidad celeste. Este dios se presenta en el mito como el poseedor del semen y las semillas de las plantas, es decir, como el principio vital del cosmos, que es destruido por las deidades del inframundo ocasionando un cataclismo cósmico.

En clara concordancia con los textos míticos del Libro de Chilam Balam de Chumayel, en el arte plástico del periodo Clásico en el área central encontramos múltiples representaciones del árbol axis mundi, e incluso desde el Preclásico, como se muestra en las estelas 2 y 25 de Izapa (figura 1).

En diversas obras, los árboles eje del mundo se esquematizan en forma de cruces, uno de los símbolos mayas más notables de la cuadruplicidad cósmica; pero siempre llevan su ave en lo alto, como lo vemos en los cetros que los gobernantes portan en los dinteles 2 y 5 de Yaxchilán (figura 2).

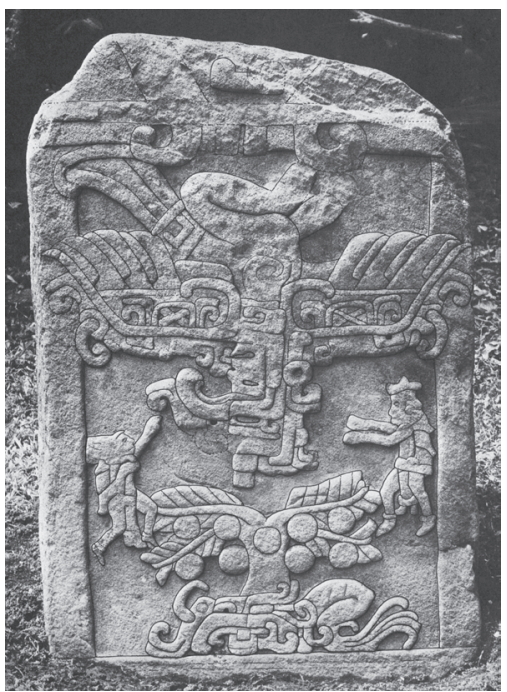

Figura 1. Estela 25 de Izapa.



Figura 2. Dintel 2 de Yaxchilán.

\footnotetext{
${ }^{8}$ Roys mostró que k'uk es el nombre maya del quetzal, unido a yaxum, pájaro verde, y traduce la frase ix kukil, ix yaxum, "Serpiente de Vida (Canhel)", como "árbol yaxum", pero dice que es un sinónimo maya de plumaje de quetzal. Y Barrera traduce esta frase como "quetzal, pájaro verde Yaxum". "Robaron su Canhel" es traducido por Roys como "despojado de su insignia", aunque da a conocer que Beltrán traduce Canhel como "Dragón” (Libro de Chilam Balam de Chumayel, 88 y De la Garza, 1995: 32).
} 
Y las cruces axis mundi más destacadas son las de la ciudad de Palenque, formadas por serpientes bicéfalas en las lápidas de los templos de las Inscripciones y de la Cruz, y por una planta de maíz en la del Templo de la Cruz Foliada.

Las tres cruces llevan al pájaro divino celeste posado en lo alto, y en la parte inferior vemos símbolos de noche, tierra e inframundo. Así, ellas expresan simultáneamente los cuatro rumbos, los tres niveles cósmicos y el axis mundi, concebido como árbol con su pájaro encima.

En cuanto a la estructura completa del cosmos, no sabemos, en realidad, si era concebido por los mayas como un cubo, como una esfera o como un romboedro o prisma romboidal, en el cual el cielo tendría forma de una pirámide de trece niveles, la tierra sería una plancha plana cuadrangular y el inframundo, una pirámide invertida de nueve niveles. En esta imagen simbólica, las cuatro regiones del cielo y las del inframundo serían las cuatro caras de las pirámides celeste e infraterrestre, que están en contacto con la tierra cuadrangular y que confluyen en la punta como unidad.

A nivel universal, la pirámide es uno de los principales símbolos de la cuadruplicidad cósmica y del centro del mundo. Claramente simboliza montaña, pero la montaña representa a su vez el cielo, en tanto que la pirámide invertida es símbolo de la caverna, que es entrada al inframundo. Asimismo, la primera es principio masculino y activo, mientras que la segunda es femenino y pasivo (Guénon, 1969: 186-7).

No tenemos suficientes datos para afirmar cómo concebían la forma del cosmos los mayas prehispánicos, pero consideramos que algunas de las construcciones piramidales que sostienen a los templos en varias ciudades mayas pueden ser símbolos de los niveles celeste e infraterrestre, así como las plazas podrían representar el nivel terrestre concebido en forma cuadrangular.

Es evidente que los basamentos piramidales de las ciudades mayas representaban a las montañas sagradas, consideradas como residencia de los seres divinos. Incluso algunos templos, como los del estilo Chenes y los de otros sitios, tienen un gran mascarón del Dragón Terrestre en la fachada, que alude a la entrada al inframundo. Esta concepción del templo como montaña sagrada es muy común en diversas religiones. Por ejemplo, dice Biedermann: "Muchos templos se han construido conforme a planos en forma de cuadrado que en su estructura escalonada deben corresponder a la montaña cósmica, como por ejemplo, en los templos de Angkor en Camboya” (Biedermann, 1993).

Pero la montaña sagrada pudo representar, a la vez, el nivel celeste, como piensan los tzotziles actuales. Esta etnia ha conservado de manera notable las ideas cosmológicas mayas que hallamos en los Libros de Chilam Balam: conciben la tierra como una superficie plana y cuadrada, y el cielo como una montaña de 13 escalones, que desde abajo se ve como una cúpula y desde fuera como una pirámide; una gigantesca ceiba sube del centro del mundo hacia los cielos, y el inframundo se concibe constituido por nueve o un número infinito de escalones. Además, describen a las montañas sagradas (en cuya cúspide habitan los ante- 
pasados divinizados y los dioses, y donde residen sus alter ego animales) como dividida en trece estratos y con una gran escalinata que los une; o sea, también con la imagen de una pirámide escalonada. "Subir a una de ellas es como elevarse hasta los cielos", dicen (Holland, 1978: 69 y 110). ${ }^{9}$

El templo-pirámide en la arquitectura maya siempre se vinculó con la plaza; son dos elementos arquitectónicos absolutamente unidos, y ello se debe a su sentido simbólico: pudieran representar el vínculo de la tierra cuadrangular con la montaña-cielo piramidal, del ámbito de los hombres y el de los dioses. En todas las fuentes se puede constatar que las plazas, que siempre obedecen a un presupuesto rectilíneo (Andrews, 1995: 7), lo cual alude a la cuadrangularidad de la tierra, eran el espacio para que el pueblo participara en las ceremonias religiosas oficiales, en tanto que los templos en lo alto de las pirámides eran el sitio para los sacerdotes, el sancta sanctorum al que sólo ellos podían acceder para realizar diversas ceremonias. El ascender a la pirámide pudiera haber significado, entonces, como para los tzotziles, emprender un viaje sagrado en el centro del mundo, realizar una ruptura de nivel, trascender el espacio de los hombres y penetrar al de los dioses, hasta llegar a la cima de la montaña sagrada, que simbolizaba el centro del cielo. ${ }^{10}$

Uno de los mejores ejemplos clásicos de la arquitectura cosmológica maya se halla precisamente en Palenque. Aquí encontramos una gran pirámide de nueve cuerpos que simboliza el inframundo, el Templo de las Inscripciones (figura 3), y un conjunto de tres templos, el grupo de las Cruces, que tanto en sus alturas como en los símbolos de sus tableros y las deidades a las que están dedicados simbolizan los tres niveles cósmicos: el Templo de la Cruz, cuyo basamento tiene trece niveles, el cielo; el de la Cruz Foliada, la tierra; y el del Sol, que se asienta sobre un basamento de nueve niveles, el inframundo (figura 4).${ }^{11}$ Hay otros tres

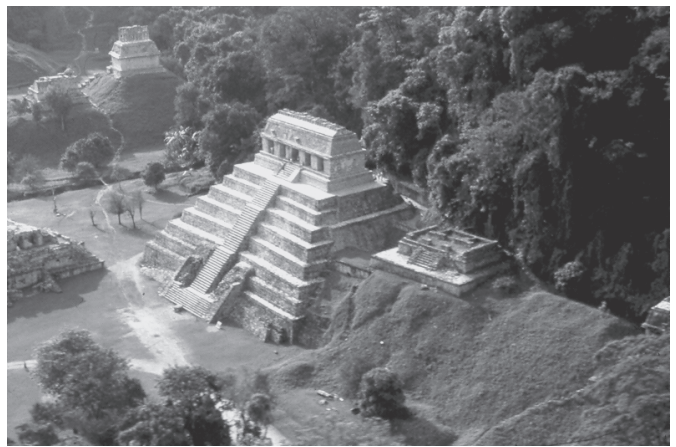

Figura 3. Templo de las Inscripciones, Palenque.

\footnotetext{
${ }^{9}$ Ver también Gossen, 1972 y 1974.

${ }^{10}$ Véase Eliade (1979: 46), ascensión al templo de Barabudur, en Java.

${ }^{11}$ Como es bien sabido, estos templos fueron construidos por K'inich Kan B'ahlam y dedicados en 690 d.C, la Cruz y el Sol, y en 692 la Cruz Foliada.
} 


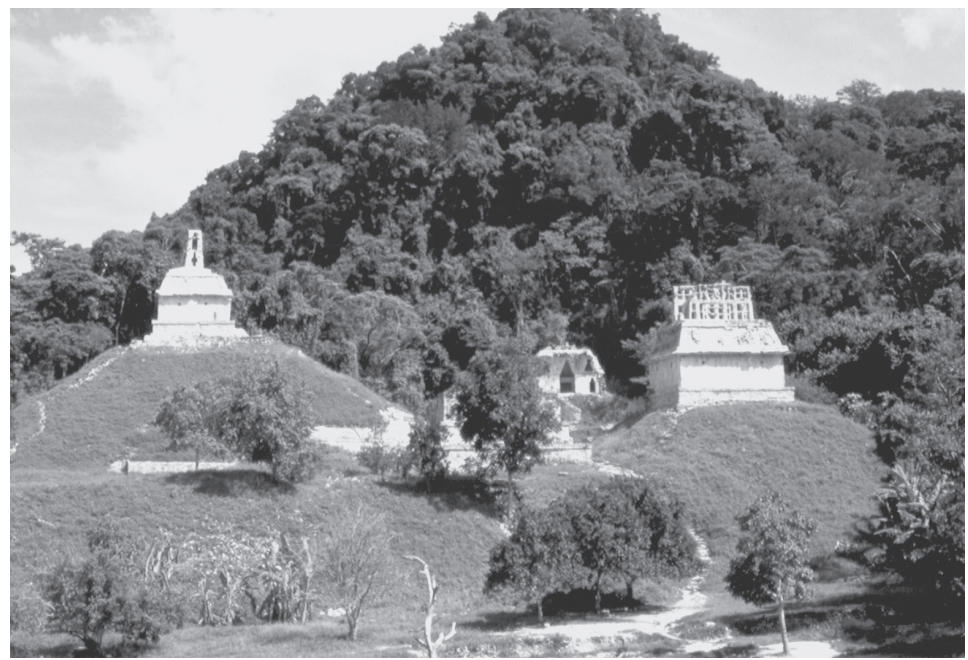

Figura 4. Grupo de las Cruces, Palenque.

templos, recientemente excavados, que se ubican al sur del grupo de las Cruces, en la llamada Acrópolis Sur, donde vuelve a aparecer el patrón cosmológico de los tres niveles cósmicos: el XIX, el más alto de los tres, se asocia con el cielo; el $\mathrm{XX}-\mathrm{A}$, en un nivel intermedio, con la tierra, y el XXI, de una altura inferior, con el inframundo, como destaca Arnoldo González (2005).

Por su parte, las deidades relacionadas con los templos de las Cruces y verosímilmente con los de la Acrópolis sur, GI, GII y GIII (figura 5), también parecen simbolizar los tres niveles cósmicos, como sus templos: GI, dios del Templo de la Cruz, es un dios celeste con atributos acuáticos, posiblemente el Sol naciente y celeste. ${ }^{12}$ GII, K'awiil, dios del Templo de la Cruz Foliada, es símbolo del nivel terrestre por representar el maíz recién nacido, la fecundidad agrícola, el relámpago y el poder de los gobernantes: es el dios de los linajes ilustres. Y GIII, dios del Templo del Sol, es símbolo del nivel infraterrestre, relacionado con la guerra, que representa al Sol Jaguar en su tránsito por el inframundo (Stuart, 2006: 88). ${ }^{13}$ Estas significaciones de las deidades de la Tríada son corroboradas por el excelente análisis de los incensarios de Palenque realizado por Martha Cuevas, en el que demuestra que GI es solar celeste y GIII, solar infraterrestre (Cuevas, en prensa).

\footnotetext{
${ }^{12}$ Aunque hay una, para mí oscura, relación con Venus, destacada por David Kelley en 1965, por su nacimiento en $9 I k$, que es el nombre calendárico de Ehécatl Quetzalcóatl. Sin embargo, esta deidad náhuatl se representa también como una serpiente emplumada, uno de los símbolos principales de la deidad celeste entre los mayas.

${ }^{13}$ Stuart interpreta las distintas alturas de los basamentos de estos templos como una jerarquía, en la que el dios celeste sería el miembro dominante de la Tríada.
} 

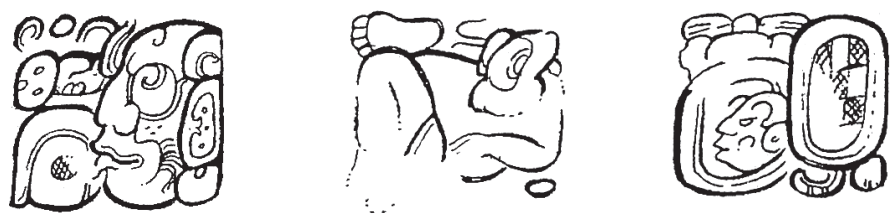

Figura 5. Dioses de la Tríada de Palenque.

Las tres deidades se vinculan además con los motivos escultóricos centrales de los tableros: GI está estrechamente relacionado con el dios celeste, representado como axis mundi en el tablero del Templo de la Cruz por su relación con el Sol diurno que recorre el cielo. GII es, entre otras cosas, dios del maíz, y una planta de maíz como axis mundi es el motivo central en el tablero del Templo de la Cruz Foliada, y GIII es el aspecto de jaguar del Sol nocturno, en su tránsito por el inframundo, y un escudo con el rostro solar bajo el cual el astro, en forma de cabeza de jaguar, se pone sobre el horizonte, simbolizado por una serpiente bicéfala, es el tema central del relieve del Templo del Sol.

Estos dioses, que conforman la llamada Tríada de Palenque, corresponden sin duda a fuerzas sagradas que fueron veneradas por todos los mayas, obviamente con distintas representaciones y nombres, y que en Palenque seguramente ya existían antes de la construcción del grupo de las Cruces por el gobernante K'inich Kan B'ahlam. Coincidimos así con David Stuart, quien dice que los nacimientos de los tres dioses registrados en las inscripciones de los templos fueron conceptualizados por los mayas como el establecimiento de tres deidades ya existentes en un nuevo orden de ser, directamente orientados hacia la dinastía palencana, después de la vuelta del treceavo Bak'tun (Stuart, 2006: 90).

Siguiendo en la línea del contenido cosmológico de las obras palencanas, la principal pirámide de Palenque que representa el inframundo es, en nuestra opinión, el Templo de las Inscripciones (figura 3). El basamento, de nueve niveles, guarda en su interior la sepultura del gran gobernante K'inich Janahb' Pakal, en el punto central más bajo; este sitio es denominado en las fuentes coloniales Xibalbá, "Lugar de los que se desvanecen", residencia de los dioses de la muerte.

El acceso de los difuntos al inframundo, según los mitos, se hacía recorriendo los nueve escalones desde el nivel terrestre, por eso la entrada a la tumba está en el piso del templo, que corresponde simbólicamente a la superficie de la tierra. El rito del enterramiento de Pakal fue, así, la representación de su descenso al Xibalbá, a través de los nueve niveles del inframundo (aunque, por sentido práctico, no simbólico, el sarcófago haya podido tal vez ser introducido a la pirámide desde el nivel de la plaza, como piensa Arnoldo González). ${ }^{14}$

${ }^{14}$ Véase entrevista en Malvido, 2006: 245-246. 
El gobernante se identificaba entre los mayas con el Sol. Esto se confirma en el Templo de las Inscripciones con la hierofanía de sombra descubierta por Linda Schele, según Horst Hartung (1992), que se produce el día del solsticio de invierno: visto desde el Palacio, el Sol se pone sobre el centro del Templo de las Inscripciones y penetra a través de él al inframundo. Así lo hizo Pakal al morir, pues el gobernante, por su posición axial en el universo, es el Sol del mundo humano. Esta significación de los gobernantes se expresa en múltiples obras escultóricas y en el Popol Vuh, donde los reyes son el axis mundi por su conciencia y por su misión de venerar y alimentar a los dioses. ${ }^{15}$

Y precisamente en la lápida que cubre el sarcófago de Pakal hay también un claro contenido cosmológico, en tanto que allí se representan símbolos de los tres niveles y de los cuatro sectores del cosmos.

\section{Itzamná en Palenque}

No entraré aquí, por supuesto, al análisis de la compleja deidad suprema y creadora de los mayas, la cual, como en muchas otras religiones, es una deidad celeste. Este ser sagrado de los mayas siempre se puede estar estudiando, pues es inabarcable. ${ }^{16}$ Sólo quiero destacar, con la finalidad de ubicar a Itzamná en Palenque, que en las obras escultóricas y pictóricas, particularmente en las del periodo Clásico del área Central, el dios supremo se representa como serpiente o dragón bicéfalo, con signos celestes y acuáticos; como serpiente emplumada; como serpiente con cuerpo de banda astral, y como serpiente alada (Tablero de los Esclavos de Palenque), entre otras formas. ${ }^{17}$

El dragón celeste, llamado por algunos investigadores Dragón Bicéfalo (Maudslay, en Spinden, 1975: 53-56), Monstruo Celeste, Monstruo Cósmico y Monstruo Cuatripartita (Schele y Freidel, 1990: 539), ha sido identificado con el dios llamado Itzamná que se menciona en las fuentes escritas coloniales de los mayas yucatecos, nombre que por ello se puede traducir como "El Dragón", y con la figura antropomorfa de los códices llamada Dios D. ${ }^{18}$ Esta identificación se basa, entre otros muchos datos (que no puedo citar aquí), en el hecho de que el dios se define en dichas fuentes como "El que recibe o posee la gracia, o rocío, o sus-

\footnotetext{
${ }^{15}$ Linda Schele también consideró al gobernante como axis mundi, pero basada en su identificación con la ceiba (1993, Afterword).

${ }^{16}$ Ver, entre otros muchos otros autores, Spinden, 1975; Thompson, 1970; Schele y Freidel, 1990; Taube, 1992, y Morales, 2002.

${ }^{17}$ Entiendo por "Dragón" un ser esencialmente serpentino, pero que tiene rasgos de ave, de lagarto, de venado y de jaguar, principalmente (De la Garza, 1984 y 1999).

${ }^{18}$ Eric Thompson (1970: 263) fue el primero en asociar al Dragón Celeste con Itzamná, en 1939, pero él lo considera una iguana y, advirtiendo el carácter dual de la deidad, habla del cosmos como una "casa de iguanas", idea que no comparto, pues las iguanas se llaman en maya itzam por su similitud con la imagen plástica del dios y no al revés, como supone Thompson. Según Ramón Arzápalo (comunicación personal), Itzamná puede traducirse simplemente como "El Dragón".
} 
tancia del cielo" (Lizana, 1988: 55), y el Dragón Celeste, además de arrojar agua o sangre o algún otro líquido vital por las fauces, tiene múltiples elementos que lo asocian con el cielo, como plumas y glifos celestes. Además, la raíz itz, según el Diccionario de Motul, significa "leche, lágrima, sudor, resina o goma por cuajar de árboles, de matas y de algunas yerbas"; al designar todo lo líquido que gotea, "parece tener una carga conceptual importante: lo lleno de vida" (Morales, 2002: 204). ${ }^{19}$ Por otra parte, el Diccionario Maya Cordemex traduce Its como "sabiduría o poder oculto"; - $a$, como "agua"; -am, como "el actor"; así, Itsam significa "mago del agua, el que tiene y ejercita poderes ocultos en el agua". Y na' significa "madre" y se asocia con la ceiba y el cocodrilo. "El árbol es la vía para llegar al cielo y la madre del género humano" (Diccionario Maya Cordemex). Estas significaciones corroboran la identificación de Itzamná con el poder sagrado del agua, es decir, con la vida; con el cocodrilo; con la ceiba, árbol eje del mundo, y con la madre.

Y en ciertas inscripciones clásicas del área central, el dios creador, padre-madre de los otros dioses, recibe también el nombre de Itzamná, como señalaré después.

El Popol Vuh, libro sagrado de los quichés, corroboraría la identificación del Dragón Celeste con el dios celeste creador Itzamná cuando dice, después de mencionar los distintos nombres de la pareja creadora, Padre y Madre, que todos ellos eran Gucumatz, Serpiente-quetzal o serpiente emplumada, símbolo principal del Dragón o deidad celeste, con cualidades acuáticas.

En algunas de las más importantes obras escultóricas palencanas (la lápida del sarcófago de Pakal, el tablero del Templo de la Cruz y el tablero del Templo del Sol) ${ }^{20}$ se representa al dios celeste supremo y creador Itzamná en su aspecto zoomorfo, y su nombre ha sido hallado en las inscripciones del Templo XIX. Éstas, a través de un análisis comparativo con los motivos simbólicos de los mencionados relieves, corroboran esa identificación del Dragón Celeste con el dios de las fuentes escritas llamado Itzamná.

En la lápida del sarcófago de Pakal (figura 6), de la que señalamos arriba el sentido cosmológico, el gran señor fue representado en el centro como símbolo del nivel terrestre; sobre él se levanta una cruz muy semejante a la del Templo de la Cruz, formada por una serpiente bicéfala, como barra horizontal, con mandíbulas superiores de cuentas de jade, y una cabeza igual de ser-

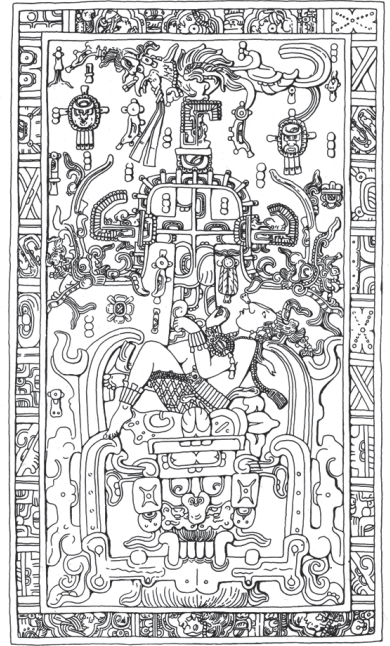

Figura 6. LÁPIDA DEL SARCóFAgo de K'Inich Hanab Pakal, Palenque.

\footnotetext{
${ }^{19}$ Véase también Freidel y Schele, 1993: 47.

${ }^{20}$ Aquí no analizaré el simbolismo de este tablero.
} 
piente remata en lo alto el eje vertical. En esta cruz se enlaza también una serpiente bicéfala de cuerpo flexible, de cuyas mandíbulas abiertas surgen caras de dos variantes del dios K. Este motivo claramente simboliza al Dragón Celeste y a la vez al axis mundi, que delimita los cuatro sectores cósmicos, por lo que se equipara con la ceiba axis mundi de los mitos cosmogónicos recogidos en los Libros de Chilam Balam. No dejo a un lado la interpretación de Schele, según la cual la cruz simboliza la idea de ascender hacia el Sol por el axis mundi concebido como la Vía Láctea (Stuart, 2006: 116), pues creo que ésta puede simbolizar el cuerpo del Dragón Celeste en su aspecto nocturno y que los gobernantes se identificaban con el Sol, significando el Sol del mundo humano, como señalé arriba.

Debajo del cuerpo de Pakal se representó la región infraterrestre, con el esqueleto descarnado de una serpiente bicéfala, contraparte de la celeste, huesos y el mascarón también descarnado de una de las caras del Dragón Celeste bicéfalo que simboliza el cielo nocturno y, por ello, se asocia con muerte e inframundo. Sobre este mascarón se asienta el llamado símbolo cuatripartita que identifica a este aspecto del Dragón Celeste; se compone del glifo del Sol, sobre el cual hay una concha spondilus, una espina de mantarraya y, en vez de las bandas cruzadas celestes que se hallan en otras imágenes de este símbolo, el glifo de muerte. La escena cosmológica tiene a los lados la banda astral, cuerpo del Dragón Celeste Nocturno.

En el tablero del Templo de la Cruz, la pirámide celeste de Palenque, (figura 7), se representa al gobernante K’inich Kan B'ahlam rindiendo culto al Dragón Celeste y al dios GI, a quien está dedicado el templo.

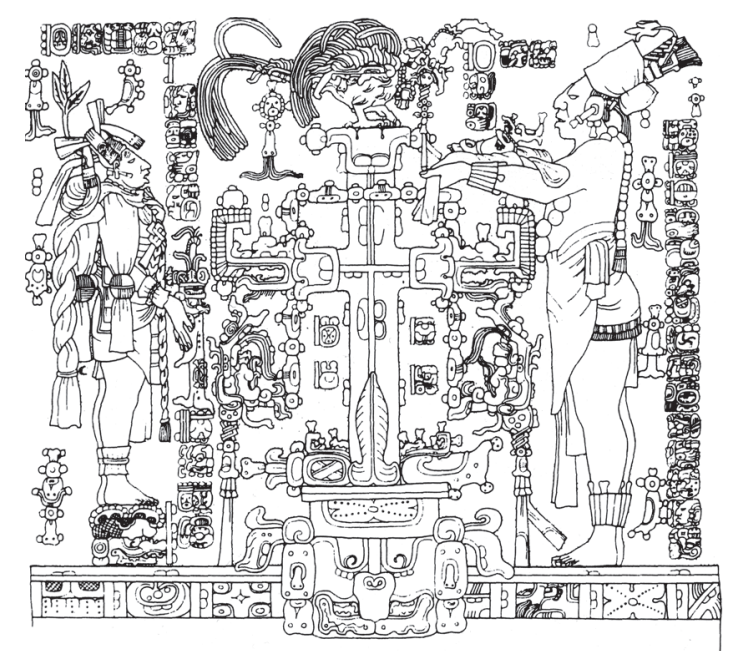

Figura 7. Tablero del Templo de la Cruz, Palenque. 
El Dragón Celeste aparece aquí también simbolizando el axis mundi en su aspecto de serpiente bicéfala preciosa. Según Schele, la inscripción se refiere a este axis mundi como "Árbol del mundo" (1993, cap. 2); al parecer no dice que sea el Dragón Bicéfalo, pero la imagen sí lo dice y lo representa en dos formas reforzando su significado tanto de axis mundi como de poder fecundante del cielo: la barra horizontal de la cruz es una serpiente bicéfala con cuerpo rígido y mandíbulas superiores flexionadas hacia arriba, formadas por cuentas de jade. Otra serpiente bicéfala con cuerpo flexible de glifos yax, alternados con cuentas de jade, se entrelaza en la cruz. Tanto el glifo yax ("nuevo, fuerte, verde-azul") como el jade simbolizan agua y fertilidad, cualidades esenciales del Dragón Celeste. En las cabezas de esta serpiente, en lugar de la mandíbula inferior pende un símbolo jade-petate, "poder precioso".

Y además se representó al Dragón Celeste en la parte inferior, con cuerpo de banda astral y mascarón descarnado, en su advocación de cielo nocturno, según mi opinión. Sosa (1984) considera que la banda astral simboliza a la Eclíptica, y Schele denomina a la deidad "Monstruo Cuatripartita" porque se identifica por llevar sobre la frente el símbolo cuatripartita: el glifo del Sol y, sobre él, una concha spondilus, una espina de mantarraya y un glifo de bandas cruzadas, variante del cielo. ${ }^{21}$ La presencia del glifo del Sol reforzaría la interpretación de que la imagen simboliza la Eclíptica; pero también la banda astral puede representar el sacbé del cielo, Vía Láctea (que sólo se ve en la noche), pues el mascarón del que surge es descarnado, lo cual demuestra su carácter nocturno que lo asocia con el inframundo; además, la deidad se ubica en la parte inferior del tablero, como en la lápida del sarcófago de Pakal.

Por su posición en el tablero y por sus rasgos nocturnos y de muerte, el Dragón Celeste Nocturno, con cuerpo de banda astral, representa en este tablero (y también en la lápida de Pakal) el aspecto destructivo de la deidad celeste, del mismo modo que su imagen en la página 74 del Códice Dresde (figura 8), donde simboliza un diluvio cósmico. En esta página el Dragón lleva patas de venado, animal relacionado con el inframundo como psicopompo (Romero, 2006), lo cual confirma la asociación con ese nivel cósmico que se representa en el Tablero de la Cruz.

El Dragón Celeste Nocturno también se esculpió en la casa E del Palacio de Palenque (figura 9), con pata de venado y sus dos cabezas: una descarnada que mira hacia arriba, aludiendo a la muerte y la oscuridad, y la otra, mirando hacia abajo y arrojando agua desde sus fauces, como en la página 74 del Códice Dresde.

\footnotetext{
${ }^{21}$ Recordemos que la Eclíptica es el círculo máximo de la esfera celeste, que en la actualidad corta el Ecuador en ángulo de 23 grados y 27 minutos, y señala el curso aparente del Sol durante el año. Schele asegura que el Monstruo Cuatripartita es el propio dios solar; esta autora, como señalamos arriba, interpreta el glifo de bandas cruzadas que forma parte del símbolo triádico como la trayectoria del Sol cruzando la Vía Láctea; es, dice, el Sol en su viaje diario a través del cosmos (1990: 540).
} 


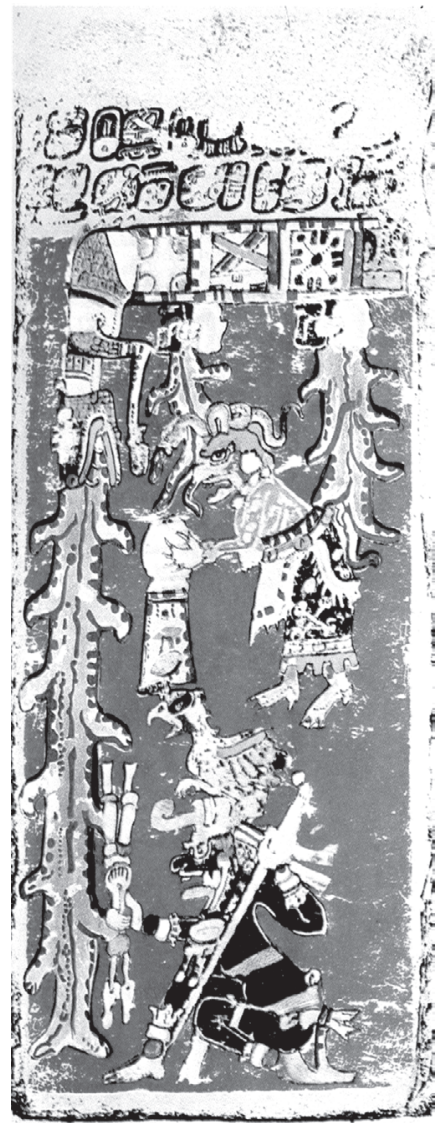

Figura 8. Página 74 del Códice Dresde.

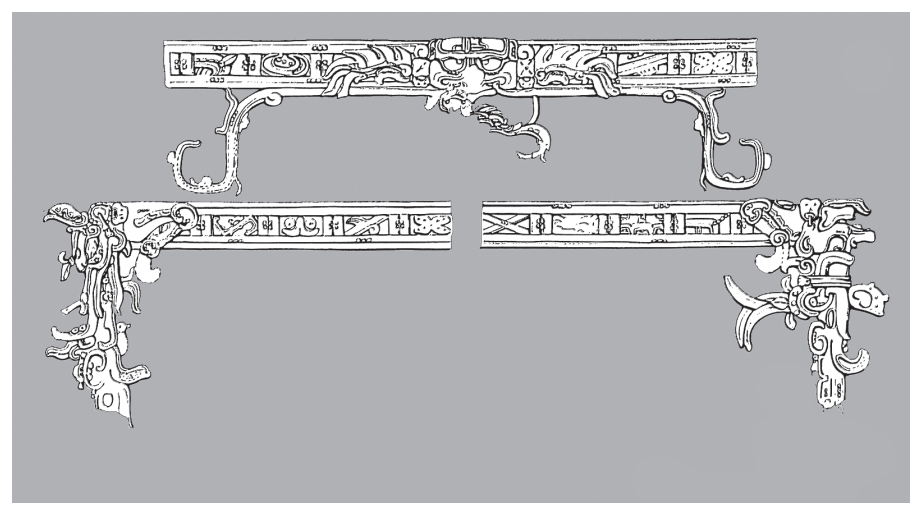

Figura 9. Relieve de la casa E del palacio, Palenque. 
David Stuart (2005: 71-75) destaca que en un texto de la plataforma del Templo XIX aparece una entidad a la que llama Cocodrilo Venado Estelar. Eric Velásquez (2006) identifica a esta entidad con el Caimán Cósmico cuya decapitación ocasionó uno de los diluvios que destruyeron un mundo anterior al actual y la equipara con el Dragón Celeste Nocturno en su aspecto destructivo, tal como se representa en la página 74 del Códice Dresde. La presencia de este ser es congruente con el hecho de que las inscripciones del Templo XXI relatan una nueva creación del mundo, pues en los Libros de Chilam Balam la creación es precedida por la catástrofe que puso fin al mundo anterior, ocasionada por un lagarto monstruoso. Velásquez, citando el Chilam Balam de Maní (Códice Pérez, 231), identifica al Caimán Cósmico con Itzam Cab Ain, al que yo llamo Dragón Terrestre, y Stuart, por su parte, afirma que el Lagarto Venado Estelar puede corresponder al aspecto nocturno del Monstruo Celeste, relacionado con la Vía Láctea (Stuart, 2005: 72). Yo considero, coincidiendo con Stuart, que el Lagarto Venado Estelar corresponde al Dragón Celeste Nocturno, pero que puede asociarse con el Dragón Terrestre por su relación con las fuerzas de oscuridad y muerte que ambos comparten. Sea cual sea su significado, indudablemente este ser representa el carácter destructivo del Dragón y por eso se asocia con el inframundo.

Por el contrario, la serpiente preciosa bicéfala emplumada, tanto en el tablero del Templo de la Cruz como en la lápida de la tumba de Pakal, en el dintel 3 del Templo IV de Tikal y en otras obras mayas, simboliza el aspecto celeste diurno del Dragón, de fertilidad y principio vital.

En síntesis, el motivo central del tablero de la Cruz representa a la deidad celeste en sus dos aspectos: cielo diurno y cielo nocturno, fertilidad y destrucción. Sin advertir que se trataba de los dos aspectos de la deidad celeste, ya Seler había considerado que Itzamná era "Señor de la vida y de la Vía Láctea", como señala Spinden (1975: 92). Ésta es la dualidad de Itzamná, mientras que el Monstruo de la Tierra, Itzam Cab Ain, "Dragón-tierra-cocodrilo" (en los textos mayas coloniales de Yucatán) es la contraparte femenina y terrestre de Itzamná, con la cual se realiza la hierogamia a la que aluden el Chilam Balam de Chumayel y el Ritual de los Bacabes, y que Morales interpreta como el propio Itzamná (Morales, 2002). Por mi parte, considero que ambos son manifestaciones o epifanías de un principio sagrado supremo, al que he llamado simplemente "Dragón" (De la Garza, 1999: 180; 1984 y 1995), y que pudiera tal vez equipararse con la deidad llamada Hunab Ku, "Dios Uno", en los textos escritos coloniales yucatecos. De él dice el cronista López Cogolludo que Hunab Ku era un "Dios único, vivo y verdadero, que decían ser el mayor de los dioses, y que no tenía figura, ni se podía figurar por ser incorpóreo" (López Cogolludo, 1954: 345).

Encima del Dragón Celeste axis mundi del tablero de la Cruz se posa el Pájaro Serpiente, que tiene cabeza de serpiente en el ala, cola y patas de quetzal y cabeza con el glifo Nen, como el dios K, rematada con diadema de concha; de su pico pende un símbolo jade-petate, como el que surge de las cabezas de la serpiente de cuerpo flexible. Yo he identificado al Pájaro Serpiente como el Sol en 
el cenit por rematar en lo alto el axis mundi (De la Garza, 1998: 66.), ${ }^{22}$ que entre los mayas parece haber estado inclinado hacia el norte (Schele, 1993:69).

El hecho de llevar al Pájaro Serpiente en lo alto identifica este axis mundi con la ceiba verde, que en el Chilam Balam de Chumayel aparece como el centro del cosmos. El árbol con su pájaro encima es además una de las imágenes universales o arquetípicas del axis mundi. El Pájaro Serpiente en este y otros relieves de Palenque se acompaña de glifos y mascarones solares, lo que refuerza la interpretación de que se trata del Sol en el cenit: en el tablero de la Cruz y la lápida del Templo de las Inscripciones, el Pájaro-Serpiente tiene a los lados escudos del dios solar, y en el de la Cruz Foliada se posa justamente sobre un mascarón solar que se ubica en la parte superior de la cruz.

Schele llamó al motivo axis mundi del Tablero de la Cruz Wakah Chan, "El Cielo Elevado"; dicho nombre, por tanto, se refiere al cielo. Sin embargo, estoy de acuerdo con David Stuart en su afirmación de que los nombres propios de las inscripciones de los tableros no hacen referencia directa a los motivos centrales. "Nosotros sabemos hoy — dice Stuart— que existe una más sutil relación entre los nombres y los símbolos icónicos de los tableros, y ellos no necesariamente corresponden de manera idéntica. Los elementos centrales de los tableros en los tres templos son mejor entendidos como profundos símbolos evocadores de las actividades y significados asociados con cada uno de los dioses de la Tríada". Y considera el motivo central del tablero como un importante símbolo de GI, por su asociación con el Sol, el cielo y la ancestral resurrección, como en el sarcófago de Pakal donde, según Schele, la cruz simboliza la idea de ascender hacia el Sol por el axis mundi (Stuart, 2006: 116). Pero ni Stuart ni Schele mencionan que ambas cruces están formadas por serpientes bicéfalas preciosas o emplumadas, representaciones del Dragón Celeste.

Por otra parte, según la lectura que dan a conocer Freidel y Schele (1993: 65-68), en las inscripciones de este templo encontramos una parte esencial del mito cosmogónico maya. En el Tablero de la Cruz se relata el origen del mundo actual en la fecha 13.0.0.0.0, 4 Ahau, 8 Kumk'u, que funge como Fecha Era de los mayas y corresponde al 13 de agosto de 3114 a. C. en el calendario gregoriano (Freidel y Schele, 1993; cap. II); se relata, asimismo, el nacimiento de los dioses creadores en el "Primer Lugar de las Tres Piedras" (como el fogón de una casa, estas tres piedras son el corazón del cosmos). A estos dioses Schele les llama la Primera Madre y el Primer Padre, Hun-Nal-Ye, dios del maíz, que "entró o se convirtió en el cielo" el 5 de febrero de 3112 a.C., acción inicial de la creación del universo (Freidel y Schele, 1993).

Pero David Stuart (2005: 162 y 66) dice que Hun-Nal-Ye es probablemente un término equivocado y destaca que un pasaje de la plataforma del Templo XIX, de K'inich Ahkal Mo'Nahb', nieto de Pakal, relaciona claramente a GI, dios del Templo de la Cruz, con Itzamnaaj o Yax Naaj Itzamná: "Primer Itzamná" o "Primera

\footnotetext{
${ }^{22}$ Claude Baudez hace suya esta idea en 2002.
} 
casa de Itzamná", nombre que quizá significa una suerte de "nuevo" o "primer" aspecto de la deidad durante la creación (figura 10). Esto coincide con el hecho de que una de las serpientes bicéfalas del tablero del Templo de la Cruz tiene cuerpo formado por glifos yax. De este modo, es Itzamná quien correspondería a esos Primer Padre y Primera Madre, como una deidad andrógina creadora celeste; es Itzamnaaj, "El progenitor de la Tríada", quien supervisa o instaura a GI como deidad en el cielo, tal vez como el aspecto celeste del Sol. ${ }^{23}$ Este texto

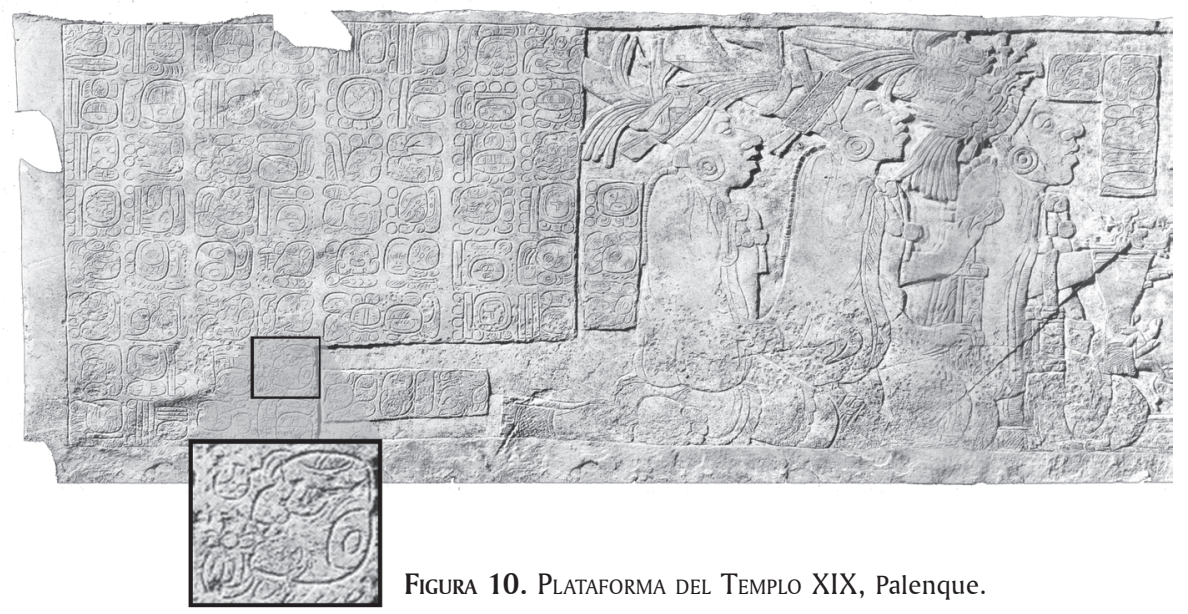

confirma, así, que Itzamná, que en su imagen antropomorfa se representa en múltiples obras clásicas de cerámica a veces sentado sobre una banda celeste o trono; que se identifica con el dios D de los códices, y que es andrógino, es sin duda la deidad celeste suprema creadora, cuya manifestación zoomorfa es el Dragón Celeste, identificado en los templos de la Cruz y de las Inscripciones con la ceiba axis mundi. Además, el propio nombre Itzamná en maya yucateco, como lo señalamos arriba, está asociado con el agua, la ceiba y el cocodrilo.

En varias inscripciones clásicas de otros sitios se indica que Itzamná fue el actor principal en el establecimiento de la nueva era, en 13.0.0.0.0., 4 Ahau 8 Cumk'u. Ejemplo de ello es la estela C de Quiriguá, donde también se relata el origen del mundo, como en el tablero de la Cruz; ahí se menciona a Itzamná como la deidad que completa la unión de las "tres piedras" de la creación, y su imagen antropomorfa se esculpió en el anverso de la obra (figura 11) (Stuart, 2005: 162).

Este dios celeste, Itzamná, mencionado en las inscripciones cosmogónicas citadas, corresponde entonces al propio Dragón Celeste representado como axis

\footnotetext{
${ }^{23}$ Ver discusión sobre el Progenitor de la Tríada en Stuart, 2005: 180. Además, en muchas religiones el dios o los dioses creadores son celestes.
} 

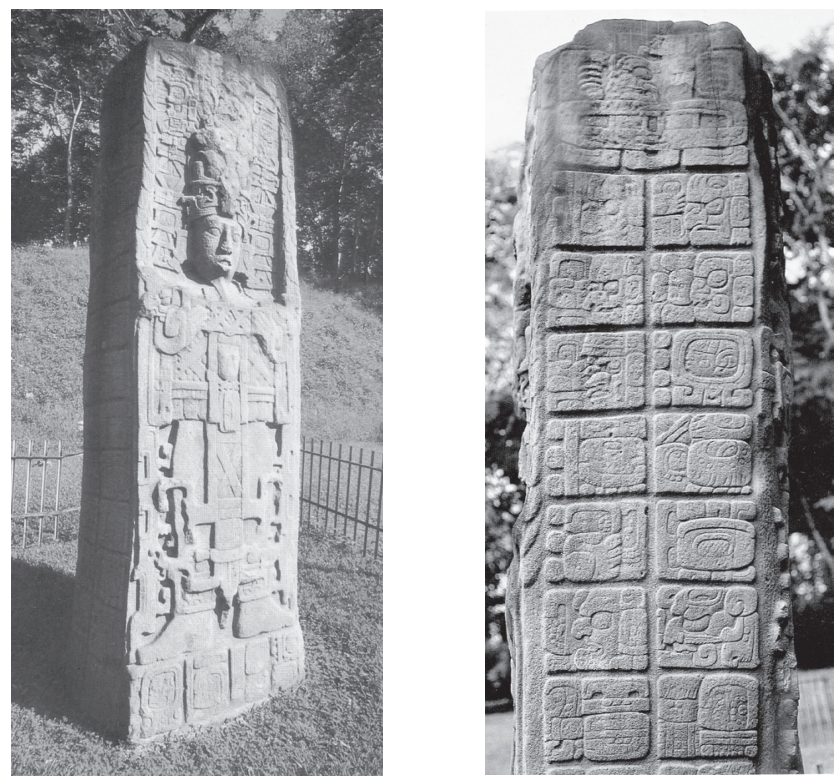

Figura 11. Estela C De QuiriguÁ.

mundi en la lápida del Templo de las Inscripciones y en el tablero del Templo de la Cruz ya que, por un lado, el Wakah-Chan de Linda Schele de todos modos se refiere al cielo, y por el otro, según las fuentes coloniales de Yucatán, el dios celeste Itzamná fue el creador del mundo, como mencionamos antes.

Dicho de otro modo, tanto el relieve como las inscripciones del Templo de la Cruz corroboran que el Dragón Celeste axis mundi ahí representado corresponde al dios antropomorfo Itzamná de los códices, dibujado con rasgos serpentinos en el rostro, y al dios creador mencionado en las fuentes escritas coloniales de los mayas yucatecos, en la inscripción del Templo XIX de Palenque y en la de la Estela C de Quiriguá. Y todo ello muestra que en el tablero del Templo de la Cruz hay otra conexión de Itzamná y GI, además de la de la plataforma del Templo XIX, aunque el nombre "Itzamná" no aparezca en las inscripciones del mencionado tablero.

Finalmente, la imagen del Dragón Celeste en el tablero de la Cruz se puede equiparar a la del dios Itzamná en su aspecto antropomorfo representado en las páginas 75 y 76 del Códice Madrid, porque ambos aparecen como el axis mundi; y en otras imágenes de los códices, como la página 69 del Madrid, Itzamná también se representa como axis mundi, reforzando esta interpretación. ${ }^{24}$

\footnotetext{
${ }^{24}$ Laura Sotelo, comunicación personal.
} 
Por otra parte, el Pájaro Serpiente o Sol celeste que remata el axis mundi en el tablero de la Cruz (y también en la lápida del Templo de las Inscripciones) podría corresponder, por eso mismo, a la deidad de los mayas yucatecos del Posclásico llamada Itzamná Kinich Ahau, "Ojo solar del dragón celeste" o "Deidad solar celeste", por unir los nombres del dios celeste y el dios solar. ${ }^{25} \mathrm{Y}$ además de Sol en el cenit, el Pájaro Serpiente sería también el Sol de la edad actual del cosmos, cuya creación se relata en el tablero, por lo que no estoy de acuerdo con la interpretación, suscrita por varios investigadores, de que se trata del Vucub Caquix del Popol Vuh, el falso Sol de la era anterior, que fue destruido por los héroes que se convertirían en el Sol y la Luna (o Sol nocturno) de la época actual.

Concluyendo, el texto cosmogónico que acompaña a la imagen cosmológica del Templo de la Cruz nos revela que ahí, en ese Centro del Mundo, montaña sagrada y cielo a la vez, tuvo lugar el acto primigenio de la creación del mundo, el 13 de agosto de 3114 a. C., y la imagen del dios supremo celeste como axis mundi, en sus dos aspectos, diurno y nocturno, confirma que el creador fue Itzamná.

Pero el mundo fue creado también en 3309 a. C. por Itzamná, como asienta el texto (mencionado antes) de la plataforma del templo XIX, realizada por K'inich Ahkal Mo'Nab, quien con un obvio sentido político hizo su propio relato del nacimiento de los dioses de la Tríada para superar a su antecesor, K'inich Kan B'ahlam.

Así, con la contradicción y la ambivalencia que tienen todas las manifestaciones religiosas, el dios celeste, supremo y creador de los mayas, donde quiera que se le sitúe y como quiera que se le represente, parece ser Itzamná.

\section{BIBLIOGRAFÍA}

Andrews, George

1995 "Arquitectura maya", Arqueología mexicana, II (11): 4-15. México: Raíces, INAH.

Barrera Vásquez, Alfredo (coord.)

1980 Diccionario Maya Cordemex. Mérida: Cordemex.

Baudez, Claude-Francois

2002 Une histoire de la religion des Mayas, Du panthéisme au panthéon. París: Bibliothèque Albin Michel (Histoire).

Biedermann, Hans

1993 Diccionario de símbolos. Barcelona: Paidós.

\footnotetext{
${ }^{25}$ Ese pájaro tiene rasgos de serpiente y cola y patas de quetzal, y el quetzal es el ave que representa al dios del cielo (Ver De la Garza, 1995).
} 
Braudel, Fernand

$1974 \quad$ La historia y las ciencias sociales. Madrid: Alianza.

Cirlot, Juan Eduardo

2002 Diccionario de símbolos, $6^{\mathrm{a}}$ ed. Barcelona: Siruela.

Códice Pérez

1950 Trad. Ermilo Solís Alcalá. Mérida: Ediciones de la Liga de Acción Social.

Cuevas García, Martha

2004 Los incensarios compuestos del grupo de las Cruces. Evidencia de rituales mayas en Palenque, Chiapas. Tesis de doctorado en Estudios Mesoamericanos, México: UNAM.

Champeaux, Gérard de y Dom Sébastien Sterckx, O.S.B.

1989 Introducción a los símbolos. Madrid: Encuentro.

De la Garza, Mercedes

1984 El universo sagrado de la serpiente entre los mayas. México: UNAM, IIFL, Centro de Estudios Mayas.

1995 Aves sagradas de los mayas. México: UNAM, IIFL, Centro de Estudios Mayas, Facultad de Filosofía y Letras.

1998 Rostros de lo sagrado en el mundo maya. México, Buenos Aires, Barcelona: Paidós.

1999 "El dragón, símbolo por excelencia de la vida y la muerte entre los mayas", Estudios de Cultura Maya, XX: 179-204. México: UNAM, IIFL, Centro de Estudios Mayas.

El libro de los libros de Chilam Balam

2004 Trad. Alfredo Barrera Vásquez y Silvia Rendón. México: FCE (Colección Conmemorativa 70 aniversario, 19).

Eliade, Mircea

1972 Tratado de historia de las religiones. México: Era.

1979 Imágenes y símbolos. Madrid: Taurus.

Freidel, David y Linda Schele

1993 Maya Cosmos. Three Thousand Years on the Shaman's Path. Nueva York: William Morrow and Company.

González, Arnoldo

2005 "El retorno de los dioses G: la consagración de tres templos en Palenque, Chiapas", Mayab, 18: 113-126. 
Gossen, Gary H.

1974 Chamulas in the World of the Sun: Time and Space in a Maya Oral Tradition.

Cambridge, Massachusetts: Harvard University Press.

Guénon, René

1969 Símbolos fundamentales de la ciencia sagrada. Buenos Aires: Eudeba.

Hartung, Horst

1992 "Investigaciones sobre el urbanismo mesoamericano y la arqueoastronomía en las últimas décadas (1960-1990)", Cuadernos de arquitectura mesoamericana (19) abril: 5-11. México: UNAM, Facultad de Arquitectura.

Holland, William R.

1978 Medicina maya en los altos de Chiapas. México: Instituto Nacional Indigenista.

Landa, Diego de, fray

1966 Relación de las cosas de Yucatán, 9ª ed. México: Porrúa.

León-Portilla, Miguel

1994 Tiempo y realidad en el pensamiento maya, $2^{\text {a }}$ ed. México: UNAM, IIH.

Libro de Chilam Balam de Chumayel

1985 Trad. Antonio Médiz Bolio, pról., introd. y notas Mercedes de la Garza. México: Secretaría de Educación Pública (Serie Cien de México).

Lizana, Bernardo de

1988 Historia de Yucatán, ed. Félix Jiménez Villalba. Madrid: Historia 16.

López Cogolludo, Diego, fray

1954 Historia de Yucatán. Campeche: Talleres Gráficos del Gobierno Constitucional del Estado, Comisión de Historia, 3 vols.

Lounsbury, Floyd G.

1985 "The Identities of the Mythological Figures in the Cross Group Inscriptions of Palenque", Fourth Palenque Round Table 1980, pp. 45-58. San Francisco: The Pre-Columbian Art Research Institute.

Lurker, Manfred,

1992 El mensaje de los símbolos. Mitos, culturas y religiones. Barcelona: Herder.

Malvido, Adriana

2006 La reina roja. El secreto de los mayas en Palenque. México: CONACULTA, INAH, Plaza y Janés.

Morales, Alberto

2002 "Unidad y dualidad. El dios supremo de los antiguos mayas: coincidencia de opuestos", Estudios de Cultura Maya, XXII: 199-224. México: UNAM, IIFL, Centro de Estudios Mayas. 
Reichel-Dolmatoff, Gerardo

1988 Orfebrería y chamanismo. Un estudio iconográfico del museo del oro. Medellín: Colina.

Romero Sandoval, Roberto

2006 "Imágenes de duelo entre los antiguos mayas", Las imágenes precolombinas, reflejo de saberes, Solanilla y Valverde (coords.). México: IIFL (en prensa).

Roys, Ralph L.

1950 "Guía para el Códice Pérez". Trad. Gustavo Vega Ibarra, Códice Pérez, trad. Ermilo Solís Alcalá. Mérida: Liga de Acción Social.

Schele, Linda y David Freidel

1990 A forest of Kings. The Untold Story of the Ancient Maya. Nueva York: Quill William Morrow.

Sotelo Santos, Laura Elena

1988 Las ideas cosmológicas de los mayas en el siglo XVI. México: UNAM, IIFL, Centro de Estudios Mayas.

Spinden, Herbert J.

1975 A Study of Maya Art, Its Subject Matter and Historical Development, Introd. y bibliografía de J. Eric S. Thompson. Nueva York: Dover Publications.

Sosa, John

1984

"Astronomía sin telescopios. Conceptos mayas del orden astronómico", Estudios de Cultura Maya, XV: 117-142. México: UNAM, IIFL, Centro de Estudios Mayas.

Stuart, David

2005 The Inscriptions from Temple XIX at Palenque. A Commentary. San Francisco: The Pre-Columbian Art Research Institute.

2006 Sourcebook for the $30^{\circ}$ Maya Meetings. Austin: The University of Texas at Austin.

Taube, Karl Andreas

1992 The Major Gods of Ancient Yucatán. Washington D.C.: Dumbarton Oaks Research Library and Collection (Studies in Pre-Columbian Art and Archaeology, 32).

Thompson, Eric

1970 Maya History and Religion. Norman: University of Oklahoma Press.

Velásquez García, Erik

2006 "The Maya Flood Myth and the Decapitation of the Cosmic Caiman”, The PARI Journal, VII (1): 1-10. San Francisco: The Pre-Columbian Art Research Institute. 